\title{
Moving hands-on anatomy teaching online: a reflection on creative solutions
}

\author{
Claire Timmins \\ University of Strathclyde, UK
}

Keywords: anatomy; active learning; creativity; Minecraft; Covid-19.

\section{The challenge}

As part of any UK-based pre-registration Speech and Language Therapy programme, all students are expected to gain knowledge and understanding of general anatomy and physiology, along with specifics related to speech and language production and processing (RCSLT, 2021). Although immensely important, it is often a challenging subject due to both the amount of information to learn and the methods of teaching (Singh et al., 2019). While traditionally the teaching of anatomy is presented as a set of lectures and rote learning by students, there have been increased attempts to innovate within this area, particularly in Allied Health subjects such as Occupational Health and Speech and Language Therapy teaching where there is less access to laboratories and cadavers. This has included the use of creative, active, and flipped learning techniques designed to engage and increase positive learning responses from students (Skinder-Meredith, 2010; Martin, Bessell and Scholten, 2014; Zimanyi, Emtage and Megaw, 2019).

On the BSc Hons Speech and Language Pathology programme at the University of Strathclyde, anatomy and physiology teaching has recently focused on the use of active learning techniques to promote deep learning of complex material. Active learning strategies are positively received by anatomy students, improving performance and attitudes (Entezari and Javdan, 2016), and are shown to reduce the gap between nonacademic and academic student outcomes (Zimanyi, Emtage and Megaw, 2019). The particular active learning strategy used in this case was the creation of paper and clay anatomical models to help students to understand the complex structures of the brain, head, and larynx. Students create clay models of the tongue and paper models of the 
larynx, and work with mannequin heads and felt, to learn about facial muscles. This creative approach to learning is positively received, and student evaluations often highlight how much they learn from these activities and how surprised they are to actually enjoy studying anatomy.

With the move to full-time online learning in 2020-21, the challenge was how to maintain these important active learning tasks and ensure the same level of engagement and learning as in in-person teaching.

\section{The response}

Prior to the start of the teaching semester, all 44 first-year students enrolled in the Anatomy and Physiology module were emailed a 'crafting shopping list' that suggested different items to purchase if they wished to take part in any anatomy craft tasks (scissors, glue, cardboard, clay). Importantly, students were assured that this was not compulsory and other means of learning would be provided if they should not or could not purchase the materials. During the initial weeks of teaching, students were tasked to create their models before each class and add to a PADLET board (padlet.com) to share with fellow students and teaching staff.

This allowed for students to work in their own time but to still receive individual feedback. While this was a good way to engage the students, I wanted to investigate digital tools that could provide a way to craft models as a group, and allow some real-time interaction. Computer games have increasingly been used in the teaching of anatomy and have been demonstrated to result in significant improvements in student performance (Moro, Phelps and Stromberga, 2020). This led to the introduction of Minecraft: Education Edition as a part of our online classes. Minecraft is a multiplayer building game (Mojang, 2021) where users engage in a virtual 3D environment. The Education platform is a game-based learning platform (Mojang, 2021) and has been used across the globe for teaching many different topics (Nebel, Schneider and Rey, 2016).

Prior to Anatomy classes a Minecraft world was created. Students were then invited to join the Minecraft world at the end of the scheduled class (as an additional learning 
experience). Once in the Minecraft world, each student was directed to build different anatomical models (see Figure 1). Not only did this allow students to create something digitally while learning about relative size and structure of the intended model, it also allowed for a different style of staff-student interaction.

Figure 1. Image of student created skulls in Minecraft Education Edition.

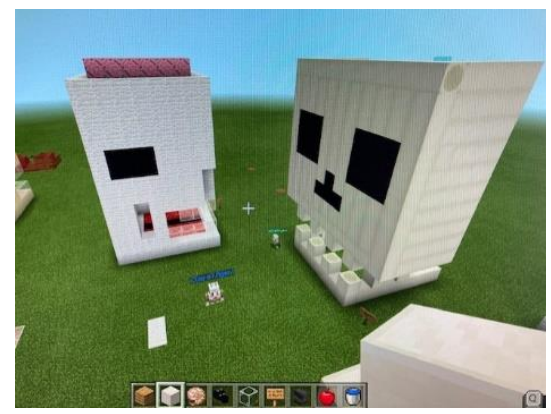

During these sessions, the instructor could walk around the models and interact with these by adding signs next to the model (see Figure 2). A chat function was also provided allowing for group feedback throughout the session.

Figure 2. Image of signs created in Minecraft Education Edition showing interaction between student and tutor.

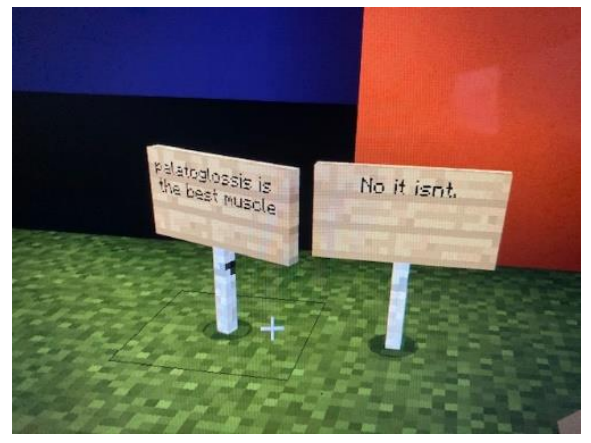

While not all students engaged with this task, the Minecraft: Education Edition platform appears to be a suitable online alternative for engaging students with creative tasks such as building anatomical models. Student feedback via module evaluation was very positive in response to this activity and those that engaged were highly motivated (continuing to engage with the platform beyond allocated class time). No specific feedback was 
requested regarding the use of Minecraft in this instance, but a scoping project is planned to investigate how to establish and encourage engagement with this platform in the future.

There were a few challenges involved in this approach. While running Minecraft: Education Edition students found their laptops unable to run any other programmes; this meant that tutor communication with students trying to access the platform was not entirely successful. Therefore along with Wi-Fi constraints, not all students were able to engage with the platform. Once the students had successfully entered the world, a small amount of training was required for those new to Minecraft.

\section{Recommendations}

Both PADLET and Minecraft: Education Edition allowed students to continue to engage with the creative Anatomy tasks throughout the online delivery of 2020-21 teaching. Although not all students completed the tasks, more students could access PADLET due to its ease of accessibility (open continually), being embedded within the virtual learning environment, and requiring minimal digital skills (photographing and uploading). Minecraft: Education Edition was very successful with students who already knew the platform and those keen to engage with digital learning tools. However, it did appear to be a challenge for those not so familiar and less motivated to engage. If considering Minecraft: Education Edition for future teaching activities, plans for training and supporting access to the platform should be developed along with attempts to address the challenge of motivating students who are not interested in the use of digital learning tools (Gabriel, Hütthaler and Nader, 2019).

\section{References}

Entezari, M. and Javdan, M. (2016) 'Active learning and flipped classroom, hand in hand approach to improve students learning in human anatomy and physiology', International Journal of Higher Education, 5(4), pp.222-231.

http://doi.org/10.5430/ijhe.v5n4p222. 
Gabriel, S., Hütthaler, M. and Nader, M. (2019). Minecraft for teaching craft, design and technology in primary school. Reading: Academic Conferences International Limited. http://doi.org/10.34190/GBL.19.026.

Martin, K., Bessell, N. and Scholten, I. (2014) 'The perceived importance of anatomy and neuroanatomy in the practice of speech-language pathology', Anatomical Sciences Education, 7(1), pp.28-37. http://doi.org/10.1002/ase.1377.

Mojang (2021) Minecraft: Education Edition. Available at: https://education.minecraft.net (Accessed: June 10, 2021).

Moro, C., Phelps, C. and Stromberga, Z. (2020) 'Utilizing serious games for physiology and anatomy learning and revision', Advanced Physical Education, 44, pp.505-507. https://doi.org/10.1152/advan.00074.2020.

Nebel, S., Schneider, S. and Daniel Rey, G. (2016) 'Mining learning and crafting scientific experiments: a literature review on the use of Minecraft in education and research', Journal of Educational Technology \& Society, 19(2), pp.355-366. Available at: https://www.jstor.org/stable/jeductechsoci.19.2.355 (Accessed: 10 June 2021).

RCSLT (2021) Curriculum guidance for the pre-registration education of speech and language therapists. Available at: https:/www.rcslt.org/wp-content/uploads/2020/08/RCSLTCurriculum-Guidance-March2021.pdf (Accessed: 10 June 2021).

Singh, K., Bharatha, A., Sa, B., Adams, O. P. and Majumder, M. A. A. (2019) 'Teaching anatomy using an active and engaging learning strategy', BMC Medical Education, 19(149). https://doi.org/10.1186/s12909-019-1590-2

Skinder-Meredith, A. E. (2014) 'Innovative activities for teaching anatomy of speech production', Anatomical Sciences Education, 3(5), pp.234-243. https://doi.org/10.1002/ase.173. 
Zimanyi, M. A., Emtage, N. F. and Megaw, P. (2019) 'Redesigning first year anatomy and physiology subjects for allied health students: impact of active learning strategies', International Journal of Innovation in Science and Mathematics Education, 27(8), pp.36-48. http://doi.org/10.30722/IJISME.27.08.004

\section{Author details}

Claire Timmins is a Senior Teaching Fellow in Speech and Language Pathology. She is a Senior Fellow of the Higher Education Academy and currently Director of Teaching and Learning for the School of Psychological Sciences and Health at the University of Strathclyde. 